\title{
A Pragmatic Approach to the Possibility of De-Extinction ${ }^{1}$
}

\author{
MATTHEW H. Slater \& HAYLEy ClatTERbUCK
}

(forthcoming in Biology \& Philosophy)

\begin{abstract}
A number of influential biologists are currently pursuing efforts to restore previously extinct species. But for decades, philosophers of biology have regarded "de-extinction" as conceptually incoherent. Once a species is gone, it is gone forever. We argue that a range of metaphysical, biological, and ethical grounds for opposing de-extinction are at best inconclusive and that a pragmatic stance that allows for its possibility is more appealing.
\end{abstract}

"Oh yeah, 'Oooh, ahhh!' That's how it always starts.

But then later there's running and then screaming...."

— Dr. Ian Malcolm, "The Lost World"

\section{Introduction}

The idea of de-extinction — or reviving an extinct species — has been around for quite a while now in popular culture (most obviously in the Jurassic Park franchise). But its possibility has also been an occasional point of serious discussion since at least the late 1970s, when the matter of the metaphysics of species was on the ascendance. In these discussions, it was often asserted that once a species was gone, it was gone for good - and not just as a practical matter, but as a matter of conceptual, biological, or metaphysical necessity. As David Hull put it, species "come into existence and pass away and, once extinct, can never come into existence again. This last claim does not concern empirical possibilities, but is a comment on how evolutionary biologists conceptualize species" (Hull 1983, p. 155; see also Hull 1976, pp. 180-183).

Fast forward three decades and some eminent biologists are talking excitedly about de-extinction (see, e.g., Church and Regis 2012). ${ }^{2}$ Some of these conversations have coincided with debates in

\footnotetext{
${ }^{1}$ Acknowledgements: A shorter, ancestral version of this paper was presented by MHS at the 2017 Pacific APA in Seattle, WA and in the "Classification in Biological Practice" workshop organized at the Vrije Universiteit Amsterdam in April 2017. MHS is grateful to participants in both audiences for helpful comments and questions on those occasions and in particular to David Ludwig, Maureen O'Malley, Thomas Reydon, and Ken Shockley; Matt Barker and Neil Williams also provided helpful written comments on a subsequent draft. $\mathrm{HC}$ was the commentator assigned at the APA whose constructive comments and extensions were subsequently collaboratively woven through the paper as a new, joint version. The paper is thus fully collaborative.
} 
ecology and conservation biology about "re-wilding" projects. For example, proponents of "Pleistocene re-wilding" argue that the managed reintroduction of animals that might approximate the ecological functionality of the large megafauna lost due to human encroachment would have positive outcomes for those ecosystems and the environment generally (Donlan et al. 2006). Famously, Russian researcher Sergey Zimov established "Pleistocene Park" in Siberia with the thought that eventually genetically engineered (i.e., more cold-tolerant) elephants might, so to say, step into the ecological shoes of the extinct wooly mammoth in order to recreate the lost ecological functions and restore what he calls "the mammoth tundra-steppe ecosystem" lost 10,000 years ago. But while such "proxy" organisms may be, ecologically-speaking, nearly as good as the lost wooly mammoth and rhinoceros of the previous epoch, it is almost irresistible to imagine bringing back the mammoths themselves.

This is precisely the kind of possibility that advocates of de-extinction have in mind. The technology that allows for sequencing and reconstructing ancient genomes is rapidly maturing. Gene-editing technologies such as CRISPR-Cas9 make it plausible that the genomes of phylogenetically closely-related species, such as the Asian Elephant, might be edited to resemble that of a mammoth genome. It is now practically conceivable that biologists could produce a living organism that is virtually genetically identical to that of a woolly mammoth (and similarly for other species). Would it be a woolly mammoth? Might extinction not be forever?

Suppose we take an optimistic view of the relevant science (we shall say more about such optimism below). What shall we make of the apparent disconnect between de-extinction enthusiasts and biologists and philosophers of biology who claim that it is conceptually incoherent? Are deextinction enthusiasts simply confused? Do they hold theses that are at odds with conventional wisdom in systematics as Hull would seem to suggest? We will argue that they are not - at least, not necessarily. None of the proffered conceptual or metaphysical objections we examine clearly succeeds in showing that de-extinction is incoherent as a general matter. Whether de-extinction is possible will depend on the classificatory framework one advocates (and often specifics of the case in question). The question of whether de-extinction is possible is thus best approached pragmatically.

We begin by asking how two approaches to the metaphysics of species are poised to handle deextinction. On the first view, that species are natural kinds (\$2), we face relatively little difficulty in accommodating this phenomenon; on the second view, that they are individuals $(\$ 3)$, there has been quite a bit more resistance. We argue that this resistance is either misplaced or inconclusive. Better, then, to examine what biological approaches to species would imply about de-extinction ( $\$ 4)$. A

\footnotetext{
${ }^{2}$ Some, but certainly not all, as we discuss in more detail in $\$ \$ 4-5$ below.
} 
major question will be whether we should admit the possibility of meta-population lineages with (potentially large) spatiotemporal gaps. While there are more pressing concerns in this domain, we argue that there does not seem to be overwhelming reason for denying that some species might go out of existence for a time and later return. We conclude that while our pragmatic approach does not rule out the possibility of de-extinction relative to certain biological interests, we suggest several political and ethical purposes for which de-extinction might make it problematic (\$5).

\section{Natural Kinds and Intermittent Instantiation}

Let us say that a species is extinct when there are no living members of that species remaining. From this starting point, we take the question of whether de-extinction is possible as the question of whether it is possible for all of the members of a species to die and then (after some intervening time) for new living members of that same species to come into existence. ${ }^{3}$ If species were natural kinds defined by intrinsic essences, as some (more or less) allege (Devitt 2008; Kitts and Kitts 1979; Wilkerson 1995), de-extinction would be (more or less) a no-brainer. For on certain traditional conceptions, a natural kind does not go out of existence when all of its instances do; it can be, as it were, "repopulated". David Hull put the thought like this in discussing the idea that natural kinds are "eternal":

$[\mathrm{N}]$ atural kinds are somehow built into the framework of the universe. At any one time, a particular natural kind might not be exemplified, but when the conditions are right, it will become exemplified. At one stage in the history of the universe, perhaps no gold atoms existed. However, when atoms of the right sort become formed, gold becomes exemplified. Hence, gold can come and go with respect to exemplification.... (Hull 1983, p. 155)

If species were individuated by intrinsic properties that could, in principle, be instantiated from time to time, then extinction would simply be the lack of instantiation of a given species and deextinction would be the re-instantiation of that species. This might be vanishingly unlikely to happen naturally and technically difficult to bring about artificially, but at first glance de-extinction poses no difficulties.

On second glance, nagging worries may arise. It might be felt that if the natural kind persists despite its lack of instantiation it is inappropriate to regard it as "extinct" - does not 'extinction' imply permanence or finality (Martinelli et al. 2014, p. 425; Gunn 1991, p. 299)? And if a species

\footnotetext{
${ }^{3}$ Advocates of the Species-as-Individuals (SAI) approach to species might object to our talk of membership and instantiation as opposed to parthood (Ghiselin 1987). For now, they are invited to substitute a congenial replacement (such as 'part of); we address SAI directly in $\$ 3$.
} 
can continue to exist in the absence of any of its members, in what sense has the species gone extinct? As Delord writes, "if one thinks in terms of products [of evolution], the so-called extinction is just a temporal gap between the occurrences of two organisms (products) of the species, and which is not a real definitive extinction. This amounts to saying that there is no real resurrection either" (2014, p. 26). On the other hand, if we think of species as evolutionary processes, "the species went definitively extinct at the end of the reproductive or living process, and so there is no resurrection at all: we only witness the results of a human modification on the living process of the bearing species, which is another stream of life than the extinct one" (26).

Delord calls this the resurrection paradox. We do not find it very paradoxical, however. That is because, insofar as we understand it, we find the "product" interpretation of the evolution of species to be acceptable. Given that, the definition of extinction offered above in terms of the non-existence of a species' members also seems acceptable and perfectly in line with paleontological usage (see, e.g., Raup 1991); extinction, on this view, is an epiphenomenon of the dying of organisms. If it fails to be "definitive" or "final", then that is just to say that we leave the possibility of de-extinction as an open question rather than a mere matter of definition. ${ }^{4}$ On this view, to say that a species has gone extinct is to say that no more members of that species remain. Normally, given the way that species come into existence and perpetuate themselves, this also means that no more members of that species will ever return to existence. But if species were natural kinds, we should not confuse what is normally not going to happen with what cannot, as a matter of conceptual or metaphysical necessity, happen. ${ }^{5}$

So far so good; but relatively few believe that species are natural kinds — at least as natural kinds are traditionally conceived. As is well known, the main problem for the traditional essentialist approach to species, is that it seriously overestimates the level of genetic homogeneity that species exhibit (cf. Devitt 2008). Various ways of relaxing the requirements of intrinsic essences exist, but it

\footnotetext{
${ }^{4}$ Some writers spend more effort attempting to square the various restoration projects falling under the broad umbrella of 'de-extinction' with this line of thought (Siipi and Finkleman 2016); since we are not much persuaded by the arguments behind this position, we will not comment on these alternative conceptions of 'de-extinction'. If, on your view, de-extinction implies finality as a matter of conceptual necessity, then you may think of the question of this paper as whether if all the members of a species should die, whether new members of that same species might later come into existence.

${ }^{5}$ We might consider an analogy to the elements. Suppose that a synthetic element Xnium is produced using means that make it very unlikely that we should ever see any more of it. As is typical of heavy elements, it quickly decays. No more Xnium. Now there is plausibly a sense in which the kind Xnium (defined by its atomic number: say, 119) persists - the sense in which if (against all odds) one made some more stuff with atomic number 119, it would be Xnium. But it would be rather misleading to say (after the few atoms of Xnium have vanished and the means of producing it no longer available) that there is still Xnium, that Xnium exists. This is "extinction" enough of us; after all, it is the kind of extinction that is relevant to the prospect of a given species evolving or interacting causally with other species.
} 
is less clear that they will be able to accommodate the idea of intermittent instantiation. Take, for example, the proposal to treat species as defined by historical essences. On Griffiths' view, for instance, "nothing that does not share the historical origin of [a given] kind can be a member of [that] kind" (1999, p. 219; LaPorte 2004; see also Okasha 2002). By making its location on the "tree of life" a necessary feature of a species, relational/historical essentialism might be thought to rule out "gappy" lineages. This is akin to thinking of species in terms of Delord's "process" interpretation. We will return to this matter below.

Treating species as Homeostatic Property Cluster (HPC) natural kinds may involve similar difficulties; for as Boyd sees it, the sorts of homeostatic mechanisms that "act to establish the patterns of evolutionary stasis that we recognize as manifestations of biological species" include such phenomena as "gene exchange between certain populations and reproductive isolation from others, effects of common selective factors, coadapted gene complexes and other limitations on heritable variation, developmental constraints, the effects of the organism-caused features of evolutionary niches, and so on" (1999, p. 165), not all of which clearly allow for the spanning of temporal gaps of instantiation. Moreover, if one took a restrictive view of the role that particular homeostatic mechanisms (or suites thereof) play in individuating HPC kinds, it would require that the same mechanism uniting the cluster of properties associated with an extinct species - and here too it's unclear whether the relevant kind of sameness would obtain with "resurrected" species.

\section{Individuality \& De-Extinction}

Matters do not get any easier when we turn to the currently popular alternative to treating species as natural kinds: treating them as spatiotemporally extended individuals. Indeed, the contrast between species seen as natural kinds in the "eternalist" sense seems to have loomed large in the formulation and defense of the Species-as-Individuals (SAI) metaphysic. But it has not always been clear whether the finality of extinction served as a result of SAI or a piece of evidence in its favor. In his booklength treatment, SAI-founder Michael Ghiselin takes the posited "spatio-temporal restriction" of individuals to mark a key contrast with natural kinds (which he treats as "classes"):

individuals are spatio-temporally restricted, whereas classes are spatio-temporally unrestricted. In other words, an individual occupies a definite position in space and time. It has a beginning and an end. Once it ceases to exist it is gone forever. In a biological context this means that an organism never comes back into existence once it is dead, and a species never comes back into existence once it has become extinct. (Ghiselin 1997, p. 41) 
On this view, once we see that organisms — paradigmatic individuals — cannot enjoy (suffer?) an intermittent existence, we should infer that species (as individuals) cannot either.

Perhaps it is supposed to be obvious that organisms and individuals in general cannot be intermittently existent. From a metaphysical perspective, however, there does not seem to be a compelling reason for concluding so — not, at least, for objects generally. The stock example is an artifact like a watch that is disassembled for repair and then reassembled (Burke 1980). ${ }^{6}$ Metaphysics of parthood and composition that incorporate Mereological Universalism (lc. Lewis 1986; 1993; see also Sider 2001) can take spatiotemporally scattered objects in stride, as any collection of things (including temporal parts) compose a further thing on this view. If those temporal parts are noncontiguous in time, we will have an intermittently existing object. We may not wish to include such an object in some domain of quantification and we may reject it on this basis as a legitimate instance of certain properties, but it is at best controversial that the fact that something is an individual entails that it cannot have a temporal gap.

What of the biological grounds for holding that species are "spatiotemporally restricted"? In fact, it's rarely been quite clear what, precisely, this term is supposed to mean (Kitcher 1989, p. 184), but in the present instance let us focus on the contention (that is apparently supposed to follow from species' spatiotemporal restriction) that species must be spatiotemporally continuous in the sense that members (parts) of a species must form an uninterrupted spatiotemporal sequence. ${ }^{7}$ Why accept this? Hull reasons that this is because " $[\mathrm{b}]$ oth replication and reproduction are spatiotemporally localized processes. There is no replication or reproduction at a distance. Spatiotemporal continuity through time is required" (1978, p. 341). But this line of argument begs the question against defenders of de-extinction. If de-extinction is conceptually possible (via artificial means), then the normal evolutionary processes by which lineages form are not the only processes that can generate new members of a species (Turner 2016) — and, in particular, they are not necessarily spatiotemporally localized processes. Inserting 'normally' into Hull's assertion above makes it unquestionably true but then irrelevant to the conceptual question of de-extinction's possibility.

We read Crane (2004) as responding to Hull's and Ereshefsky's (1991) arguments concerning species' necessary “non-gappiness” along similar lines. As she points out, Hull's argument commits a modal fallacy. Suppose we define species as entities capable of evolution by natural selection, which

\footnotetext{
${ }^{6}$ Now, one might argue that the watch does not go out of existence but rather remains in pieces on the repair bench (or wherever its pieces are scattered). But in either case, we have spatiotemporal scatter - either in the spatial or temporal dimensions - putting pressure on the claim that species are spatiotemporally restricted.

${ }^{7}$ This concept, of course, can also be interpreted in different ways. Does it apply, for example, in a case in which a single cell is preserved of a multicellular organism that is subsequently "regrown"? Would it apply if all we have is a strand of DNA? We will address such questions below.
} 
in turn requires spatiotemporally-continuous processes. This does not entail that species are necessarily spatiotemporally continuous any more than the fact that cars are capable of running on gasoline entails that every car is necessarily gassed up (Crane 2004, p. 161)!

Turning our attention back to the analogy Ghiselin drew between species and organisms, we can see this as being similarly inconclusive for the present point. For one, some philosophers interested in the metaphysics of organismal resurrection for religions concerned with an afterlife have offered compelling cases for its coherence (Hershenov 2003; cf. van Inwagen 1978). For two, the analogy between species and organisms may be resisted. Even if it is true that the self-same organism cannot conceivably be brought back into existence — and it scarcely seems obvious to us that it cannot — it is not clear that the same should hold true of species. The parts of species, it should be admitted on all sides, typically possess considerably less functional integration among their parts than organisms (Kitcher 1989).

The species-organism analogy thus seems to be of limited use for detractors of de-extinction. Indeed, it is sometimes a source of confusion. For example, in discussing the SAI approach to deextinction, Delord discusses a thought experiment of Gunn's (1991) comparing the extinction of a species to the death of an organism, writing:

Hitler's clone, an individual possessing the same genetic information as Hitler, would never be the same individual, and far less the same person, because he would not be entirely determined by his genotype, but also by epigenetic effects and by the environment. Similarly, because the ecological environment of a recreated species will be different from that of the original (especially if the lapse between extinction and recreation is long), the species will become another species, that is, it will be different from what it would have been if it had evolved naturally. (Delord 2007, p. 660; see also Delord 2014, pp. 28-30)

But this line of argument is a red herring. What is required for the resurrection of a species is not the reproduction of the self-same organisms or physically exactly identical organisms (e.g., with parts in the same functional arrangement as they were prior to their death). All that is required is the production of organisms that belongs to the same species. Grant that a clone of Hitler would not be Hitler; but this organism would presumably still be a human (Siipi 2014, p. 83). Delord's mention of ecological difference presumably would not apply here. Nor, in general, are the grounds for thinking that the ecological environment(s) of the cloned individuals would be (a) necessarily different or (b) necessarily relevant to their species membership.

We will return to concerns about epigenetics in the next section. For the moment, though, it is important to remember that while efforts to revive long-extinct species are flashy and attentiongetting, de-extinction might also be used as a sort of "ecological defibrillator", returning recently lost 
species to ecosystems that retain an open niche. ${ }^{8}$ Note that in such cases, our ability to determine whether a putatively restored species in fact bears sufficient physiological/ethological similarity to its putative conspecifics to satisfy relevant criteria of sameness may be quite a bit better than in cases involving long-extinct species. We should thus be cautious to over-generalize from the problems facing some dramatic de-extinction efforts to the possibility of any de-extinction.

\section{Species Concepts: A Pragmatic, Pluralistic Approach}

The above discussion suggests that there is nothing in the metaphysics of either natural kinds or individuals that obviously precludes the possibility of de-extinction. Let us instead consider what various species concepts say about the kinds of similarity or relations that must obtain among individuals or populations in order for them to constitute a species and ask whether these kinds of relations can preserve specieshood across the kinds of gappy existences that would be involved in deextinction. Here, we endorse pluralism and pragmatism both across and within species concepts. Our interests in pursuing de-extinction will determine both which species concept is relevant in a given case and what measure of similarity or relatedness suffices for specieshood within a particular concept.

\subsection{Easy Cases}

Let's begin with the most straightforward cases: Mayr's (1963) Biological Species Concept (BSC), Mallet's (1995) genetic cluster approach, or any of the various phenetic approaches (e.g., Sokal and Sneath 1961). On these accounts, whether some organisms belong to the same species (are "conspecific") is determined by whether they are inter-fertile or whether they exhibit certain kinds of intrinsic genetic or phenotypic similarities. And nothing about these criteria rule out a period of non-existence of members of a given species. This is perhaps most obvious for the latter two species concepts. In the case of the BSC, one might worry about the practical impossibility of empirically verifying the potential for interbreeding - would a cloned mammoth be able to successfully interbreed with the genuine article? But of course, this is a perennial difficulty for the BSC, whether we are considering the reproductive compatibility/isolation of species for which we only have fossil evidence or of organisms in the wild that might not readily manifest their interbreeding potential. ${ }^{9}$

\footnotetext{
${ }^{8}$ Indeed, one might even explicitly prepare for a de-extinction attempt as a contingency plan for species that are particularly threatened.

9 Siipi and Finkelman (2016) advocate for an "operational" interpretation of the BSC that requires conspecifics be able to "actually interbreed" with each other, thus entailing that de-extinction is conceptually impossible on this interpretation of the BSC (2016, p. 5, notes 2 and 3). This strikes us as an overly demanding
} 
Certain theoretical or practical interests might encourage us instead to employ the Ecological Species Concept (ESC) $)^{10}$ — say, if we were dealing with phyla for which the BSC wasn't sufficiently discriminating (e.g., some plants) or if our main interest in de-extinction had to do with the ecological role of the engineered species. The question of whether a cloned mammoth is a genuine mammoth would in this context depend on whether it plays a sufficiently similar ecological role as did the extinct species. Within this concept, too, there is room for pluralism. For example, if we are interested in bringing back mammoths to encourage the growth of grasslands that will prevent the thawing of the permafrost, then similarity with respect to dietary or migratory habits will be the relevant measures of ecological similarity. If we are interested in the role that mammoths played with respect to predators, other measures of ecological similarity will be emphasized.

Here, though, de-extinction introduces new empirical complications - particularly if the putative de-extinction spans an extended time. Consider a toy example. Imagine that after the dodo went extinct, no other organism managed to "take over" its ecological niche — its "job went unfilled". Does the niche remain through changes to other aspects of the ecosystem (including

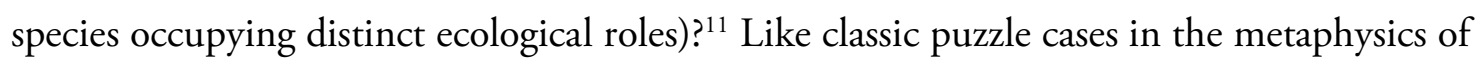
persistence, the answer may be unclear, depending on the details of the imagined case. And we can of course imagine details that make answers especially difficult — say, by imagining partial/incomplete niche takeovers or by introducing holistic complications (as in especially ambitious version of Zimov's Siberian steppe ecosystem restoration where multiple extinct species are "brought back" more or less at once).

Once again, however, such complications are not insuperable; nor do they impugn the general possibility of de-extinction. There might be cases where we scratch our heads about whether we should regard some organisms as of the same species as the dodo or wooly mammoth, but this does not mean in those cases — relative to a particular species concept and specification of its "tolerances"

\footnotetext{
interpretation of operationality (note that, strictly interpreted, it would require that two organisms of the same sex or two organisms separated by an appreciable number of generations could not be regarded as conspecific either). We leave this issue to one side in the present context. We will essentially agree with the broader point that Siipi and Finkelman make that whether we regard de-extinction as possible will depend on how we conceptualize species.

${ }^{10}$ According to which species are defined by their occupancy of a particular ecological niche (van Valen 1976).

${ }^{11}$ One might also pressure advocates of the ESC to be more specific about the kind of ecological role that is constitutive of species identity, putting pressure in turn on their compatibility with de-extinction. For example, is it supposed to be a purely functional matter whether a population fills a particular ecological niche or need the relationship make reference to other particular species (in which case, perhaps, a holism might apply)? We are not sure what defenders of the ESC would want to say here and leave the matter open; thanks to Ken Shockley for raising this question.
} 
(of whether certain aspects of the concept apply) and relevant background information - that there is not a fact of the matter about whether they are. Nevertheless, it is conceivable that in some practical contexts - even when a particular species concept seems most relevant - there will be no uniquely appropriate specification of its tolerances that will permit a univocal answer about whether a de-extinction has been achieved (especially given the considerations to which we turn in the next two subsections). But none of these possibilities rule out the possibility of clear cases where some organisms do satisfy the same species concept as did organisms of a (formerly) extinct species.

\subsection{Epigenetic Concerns}

It is sometimes remarked - as a point of criticism by de-extinction critics or caution by its supporters - that because surrogate parents of a different species will presumably be needed for at least the first generations of a putatively restored species (e.g., elephants have been suggested as likely surrogates for a resurrected mammoth), we should not regard the cloned organisms as truly of the extinct species (Delord 2014, p. 29). They will, after all, be chimeras of a sort, incorporating the cellular machinery (including mitochondrial DNA) of the surrogate organism's enucleated cell (Shapiro 2015, pp. 157-8).

We can sharpen this criticism. Genetics is not everything: the characteristic features and behavior of many species is a product of their epigenetic inheritance (including DNA phosphorylation/methylation, mitochondrial DNA, maternal microbiome, behavioral training, and so on). Would a genetic clone of a mammoth born of an Asian elephant behave like a mammoth? Perhaps not, but the worry is inconclusive for three reasons.

First, we are used to dealing with cases where the epistemic utility of a category is impugned by unusual circumstances (Siipi and Finkelman 2016, p. 8). An Asian elephant born of an Asian elephant in a zoo does not behave like an Asian elephant in the wild, but few would be inclined toward the further step of claiming that the behaviorally-impoverished organism is not in fact of the same species as its wild cousins. After all, relevant species concepts still apply. This might make it useless as a subject of study (for certain research questions) but that's as it may be. To claim that some species are natural kinds need not imply that any members of that species will contribute equally to our inferential/explanatory projects.

Second, the importance of such epigenetic influences varies widely across species. Just as discussions critical of de-extinction often default to considering the most challenging feasible cases, it also tends strongly toward the "zoocentric" (O’Malley 2010, p. 535), largely ignoring cases involving plants or microbial life where such epigenetic influences are of more limited significance. 
Finally, while we can only speculate on the technological possibilities, we should probably not presume that de-extinction will necessarily omit or "contaminate" epigenetic information particularly in cases where a de-extinction effort could be planned in advance. Once again, if we are interested in the conceptual possibility of de-extinction, we must (to a certain extent) abstract away from our present technical resources for achieving it - e.g., not assuming that cross-species surrogacy must be involved. It is not out of the question, after all, that epigenetic or cytoplasmic information could be artificially modified. ${ }^{12}$ For many legitimate biological purposes, degrading (or modifying) the epigenetic inheritance between populations need not affect whether an appropriate species concept applies (Martinelli et al. 2014, p. 423). Moreover, we can separate the question of whether a given population represents a natural kind (for certain epistemic interests) from the question of whether that population is one and the same species (see Slater 2013, \$6.4). For example, significant epigenetic differences might not preclude the possibility of interbreeding (on the BSC) or might leave intact enough phenetic similarities to permit them to serve as natural kinds with respect to some inferences but not others. A passenger pigeon raised by a different species might not learn to fly in the same way as a "natural born" passenger pigeon — so it might not serve as a natural kind with respect to pigeon locomotion — but it nevertheless might be a good model of adult size, mating behaviors, and so on (Ehrenfeld 2013).

\subsection{Phylogenetic Approaches}

As with the SAI metaphysics of species, phylogenetic approaches to species pose the greatest prima facie challenge to the possibility of de-extinction. Consider Hull's interpretation of these approaches as they impact this question (seen as the question of whether species might in some sense are “eternal"):

I do not see how anyone who thinks species are things that evolve can maintain that they are in any sense eternal.... The dodo is now extinct. As unlikely as it might be, perhaps a species of wild turkey might produce a species that is genetically identical to the dodo.... Do these organisms belong to one species or two? As I read both Wiley (1981) and Nelson and Platnick (1981), the answer to this question is two. All three of these authors require genealogical connections for species status. (Hull 1983, p. 155; see also Hull 1981, p. 147; Brogaard 2004, p. 255; Garvey 2007, p. 150)

\footnotetext{
${ }^{12}$ Clearly more needs to be said on this matter (here we are grateful to Maureen O'Malley's feedback); granted, it seems unreasonable to simply presuppose "Star Trek"-esque technology (Heisenberg Compensators $\approx$ Epigenetic Compensators?), but nor is it obvious to what extent one ought to supply a technical "how possibly" account of the relevant background.
} 
As before, the relevance of Hull's point to the possibility of de-extinction in general is unclear. Presumably the group including the dodo and his imagined "swamp" dodo would fail to be monophyletic and might for this reason be reckoned as an illegitimate taxon. Crane's response to this possibility is once again wise:

It is difficult to determine from their actual usage how evolutionary biologists might treat species in remote counterfactual situations [such as the reappearance of a genotype]. Does the prohibition against re-evolving species flow from the principle of monophyly, as Hull thinks, or does the principle of monophyly flow from the fact that genotypes (contingently) do not re-evolve?... If we consider a counterfactual situation in which genotypes re-evolve with some frequency, it is not so clear that Hull's conceptual claim is correct. Under those circumstances, the principle of monophyly might not be so important or convenient to taxonomists. Biologists might want to say the dodo evolved several times. Actual biologist usage is unlikely to settle the matter. (Crane 2004, p. 161)

We can consider other ways of putting pressure on the relevant aspects of biological practice. Consider Kitcher's well known example of Cnemidophorus tesselatus which, he reports, naturalists believed to have evolved by a hybridization event between two distinct species: $C$. tigris and $C$. septernvittatus. Now imagine that $C$. tesselatus goes extinct but that later a similar hybridization event produces organisms that are indistinguishable from the extinct species. Kitcher writes:

I claim that this would have been the correct description to give of a sequence of events in which first hybridization was followed by extinction and later by second hybridization. For, supposing that the clones founded in the first hybridization fall within the same range of genetic (morphological, behavioral, ecological) variation present in the population that has persisted to the present, what biological purpose would be served by distinguishing two species? To hypothesize "sibling species" in this case (and in like cases) seems to me not only to multiply species beyond necessity but also to obfuscate all the biological similarities that matter. (1984, p. 315)

Of course, Kitcher's assessment here might be resisted on the grounds that we cannot properly consider the second lineage of $C$. Tesselatus to be continuous with the first inasmuch as organisms of the first lineage are not causally related to the second by ancestor-descendant relations; rather, the more recent lizards have as ancestors descendants of the original lineage's ancestors. But notice that in the case of a putatively resurrected mammoth, the lineage topology will be quite a bit simpler. Moreover, the later organisms would presumably be causally linked to the earlier ones.

Nevertheless, a cladist may still argue that the revived mammoth population will not be linked by the right kinds of genealogical relationships. However, it is not entirely clear what these necessary causal relationships are. As Kitcher (1989) argues, there is room for pluralism about what counts as a 
proper ancestor-descendant relationship even within phylogenetic accounts, as "there is no single, objectively right way" to divide a lineage into species, and "various ways of proceeding offer partial solutions, emphasizing some biological features of the situation and downplaying others" (p. 154). In essence, Kitcher seems to be arguing for pluralism within a pluralism. At the first level, we have the question of which species concept to employ in a given case; having alighted on a phylogenetic approach, there remains a plurality of ways to divide lineages into species. Similarly for other species concepts: how low must barriers to interbreeding be, how robust gene exchange, how analogous ecological roles, and so on?

In the case of phylogenetic approaches, one of the key questions to be answered is what kinds of causal processes count as establishing species-preserving genealogical connections? Consider populations $A$ at $t_{1}$ and $B$ at $t_{2}$, where there is some gap (that is, a period during which no instances of $\mathrm{A}$ or $\mathrm{B}$ exist). What sort of causal connection $\mathrm{X}$ between $\mathrm{A}$ and $\mathrm{B}$ is required for $\mathrm{B}$ to be part of the same lineage as A? Contrariwise, what sort of "deviancy" is sufficient to disrupt species identity?

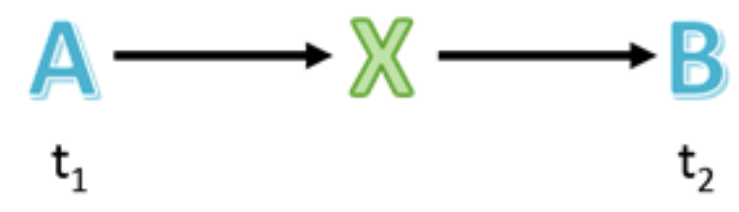

Unlike Hull's "swamp-dodos", the properties of the putatively resurrected mammoths are counterfactually-dependent on those of the long-dead organisms. However, on the phylogenetic account, mere counterfactual dependence will not suffice for species identity. For example, the traits of two distinct species co-evolving with one another will counterfactually depend on one another. More to the point, if biologists engineered cold-tolerant elephants by altering their genomes from scratch while taking, as it were, aesthetic inspiration from long-dead mammoths, traits of the new population would counterfactually depend on the old but would arguably lack the right kinds of causal connection to preserve species identity.

Perhaps, then, a necessary condition on this causal connection is that there be some material substrate that persists between $t_{1}$ and $t_{2}$ to ground the counterfactual dependence between $A$ and $B$. However, this condition is either too restrictive or will often permit de-extinction. In normal cases of species persistence, there need be no actual physical DNA molecules or other material substrate which persist from A to B. On the other hand, weaker requirements of material connectedness, such as material overlap (Greisemer 1999; 2000) or spatiotemporally linked copying events, may be satisfied in typical de-extinction cases in which genetic sequences uncovered from the extinct 
population are used to reconstruct a viable genome. ${ }^{13}$ Once again, however, we can clearly add complications to our imagined scenarios that might result in hesitation about whether we are talking about one lineage or two. It is likely that de-extinction from ancient DNA will require some educated guesswork to fill in some of the inevitable gaps in our reconstructions of the extinct organisms' genomes. We flirt with a sorites problem when asking questions like "how much guesswork or foreign DNA sequences are compatible with considering the engineered organisms as belonging to the same lineage?" But even if such questions vex us, this does not mean that there will not be straightforward cases of gappy lineages with continuity of genetic material and thus of deextinction.

Granted, these genetic copying events may be separated by thousands of years, which might incline us to judge that the causal link in question is too deviant for specieshood. However, nature provides many cases of species persistence across long gaps between reproductive events. Desert ephemeral plants, such as those responsible for superblooms in the California desert after particularly wet winters, may lie dormant for long periods of time until suitable conditions are met. Increasingly, scientists are exploiting adaptations for long dormancy periods to revive ancient plant lineages. In an extreme case, Yashina, et al. (2012) successfully propagated fertile Silene stenophylla plants from 30,000 year old fruit tissue recovered from Siberian permafrost. We can imagine a scenario in which this tissue was the last remaining vestige of an extinct $S$. stenophylla population, such that there existed a millennium-long period without any living individuals of the species. Scenarios like these may become increasingly common, with projects like the Svalbard Global Seed Vault acting as global "gene banks" that can be used to regenerate useful species. In the event that, say, potatoes are wiped out by a disease, only to be revived from seed one thousand years later, it seems overwhelmingly plausible that these new individuals would still be potatoes. Furthermore, many de-extinction events may involve smaller spatio-temporal distances than these biologically "normal" cases, reviving very recently departed species.

Nevertheless, there does seem to be a relevant difference between the cases sketched above, in which humans merely provide the conditions for normal biological reproduction to take place, and de-extinction efforts involving significant human intervention into the reproductive process itself. Perhaps the causal chain linking extinct species A to a revived population B involves intervening steps, $\mathrm{X}$, are seen as too deviant for species identity. However, upon further examination, it is not

\footnotetext{
${ }^{13}$ Godfrey-Smith (2009) argues that even this weaker requirement of material overlap is too restrictive because it rules out cases of formal reproduction, such as when a virus reproduces using only the machinery of its host cell.
} 
obvious that such human intervention cannot count as the right kind of causal connection between ancestors and descendants.

First, in many biologically normal cases of reproduction, the intervention of another species or some other type of external reproductive support serves as a link in a rather complex speciespreserving causal chain. An extreme example is the parasitic worm Spinochordodes tellinii. Its larvae are hatched in shallow water, where they are eaten by small insects like mosquitoes. These, in turn, are consumed by grasshoppers, and it within this host body that the worm grows significantly. Then, when it is time for the worm to lay its eggs, it releases proteins that cause the grasshopper to plunge to its death in a body of water (thus earning S. tellinii the nickname of the "zombie parasite"). There, the life cycle begins again.

Human intervention, specifically, plays a significant role in the "normal" reproductive processes of quite a few species. For example, there exist certain breeds of dog that are capable of producing fertile offspring...but only with a little human help. If a Great Dane-Chihuahua mix comes into fashion, producing a large population of "Danhuahuas," this offspring population would still be part of the same species as its parent breeds. Humans are an important part of the selective environment of domesticated species and increasingly many others. It is natural, in this case, to think of humans as part of the selective environment of Canis familiaris, and therefore, human intervention does not seem to break the right kinds of causal links between dog populations.

The critic of de-extinction might reply that it is not human intervention per se that is so problematic but rather the form or extent of such intervention. In the cases we mentioned above, humans merely create the conditions under which normal biological reproduction can occur. However, the causal links between A and B that are responsible for genealogical relatedness - the transmission of genetic information from one generation to another via normal DNA replication, gamete formation, and reproduction — do not essentially involve human activity. On the other hand, de-extinction projects will typically involve human reconstruction of DNA, the implantation of DNA into a denatured host cell, and the placement of that cell into a member of a different species for gestation (presumably). However, here too the lines between "biologically normal" or "natural" processes and those involving deep human intervention are blurring (such is life in the Anthropocene). Genetically modified tomatoes are still tomatoes; gorillas conceived by in vitro fertilization are still gorillas (cf. Lee 2003). Likewise, a genetically engineered mammoth, born of an Asian elephant, may still, for certain purposes, be reckoned a mammoth.

Those who advocate for treating species as natural kinds may be inclined to evaluate specieshood (or kindhood) in terms of the inferential and explanatory purposes to which such organisms might be put. Our knowledge of mammoth ethology and physiology is limited. Would cloning mammoths 
serve to fill in these gaps? It will depend on the details and our background knowledge. Possibly, such organisms would be unreliable models of ethological inferences but excellent models for physiological inferences - that is, they might function as natural kinds for some purposes and not others (Slater 2015). ${ }^{14}$ For those purposes where it is appropriate to regard them as of a kind, it will be correspondingly appropriate to regard them as mammoths. But are they real mammoths? That is a question that the pragmatist will not recognize as univocally answerable.

\section{The Pragmatic Context for De-Extinction}

Near the conclusion of her book-length treatment of How to Clone a Mammoth, Beth Shapiro offers the following response to the assertion that "the product of de-extinction won't be the same thing as the original species":

That is correct. It won't be the same.

In Stewart Brand's half of his written debate with Paul Ehrlich, he writes: "If it looks like a passenger pigeon and flies like a one, is it the original bird?" My answer is no, it's not the same, and by this point in the book it should be clear why my answer is no. Crucially, however, I don't care that it's not the same thing as the original, and I'm pretty sure that Stewart doesn't care, either.

The task ahead is not to make perfect replicas of species that were once alive.... The goal of de-extinction is to restore or revive ecosystems, to reinstate interactions between species that no longer exist because one or more of those species are extinct. (Shapiro 2015, p. 205)

On its face, this might seem like an expression of pragmatism: what matters to Shapiro seem to be the re-creation of certain lost ecological interactions; if a putatively resurrected species is "not really" the same as an extinct species, so be it — the project may still be worth pursuing. Something similar seems to be going on in IUCN's (2016) “Guiding Principles on Creating Proxies of Extinct Species for Conservation Benefit"; they write:

The term 'de-extinction' is misleading in its implication that extinct species, species for which no viable members remain, can be resurrected in their genetic, behavioural and physiological entirety. These guidelines proceed on the basis that none of the current pathways will result in a faithful replica of any extinct species, due to genetic,

\footnotetext{
${ }^{14}$ Our pragmatic approach to the relevant conceptual tolerances for causal connection might also be brought to bear on the question we left aside above of whether the HPC account of natural kinds might apply to putatively resurrected species - viz. whether the same homeostatic mechanism was responsible for the stability of a property cluster associated with a species taxon exhibiting a temporal gap in those properties' instantiation.
} 
epigenetic, behavioural, physiological, and other differences. For the purposes of these guidelines the legitimate objective for the creation of a proxy of an extinct species is the production of a functional equivalent able to restore ecological functions or processes that might have been lost as a result of the extinction of the original species. Proxy is used here to mean a substitute that would represent in some sense (e.g. phenotypically, behaviourally, ecologically) another entity — the extinct form. Proxy is preferred to facsimile, which implies creation of an exact copy. ${ }^{15}$

In both instances, however, we worry that there is a "bait-and-switch" akin to what we saw in Delord's discussion of the Hitler-clone thought experiment: we see no evident reason for requiring an organism to be "(exactly) the same" or "a facsimile" in order for an extinction to have been reversed. Nevertheless, we share Shapiro's pragmatic leanings; we simply take them further: whether some organisms are "the same" as some others depends on the more precise concepts one deploys (and how one deploys them). ${ }^{16}$ Our our pragmatist, pluralist approach to de-extinction allows us to focus on the roles that species play in various projects. One might, for example, share Shapiro's emphasis on ecological properties in thinking about sameness without feeling forced into a negative answer to whether a cloned mammoth is the same kind of thing as extinct mammoths - which is not to say that they will be epistemically suitable for certain sorts of projections, irrespective of our interests - because of extensive human involvement, significant spatio-temporal gaps, epigenetic differences and the like.

Such differences may not inhibit revived populations from counting as the same species relative to certain biological interests. However, species are not merely imbued with biological significance. We also have ethical, political, legal, aesthetic, and other projects that centrally involve species qua species. While we might lament the undue emphasis on specieshood in such projects, as long as species concepts continue to guide ethical and political decision-making, it will not be possible to side-step the issue in the way that Shapiro and others might hope. Here, we will suggest two ways in which de-extinction might fail to genuinely revive species in the ways that matter for these projects.

First, species designations play a central role in conservation efforts, most notably in the granting of legal protections to groups of organisms under the Endangered Species Act and similar laws. Although some biologists may express discomfort with species being the relevant category for conservation measures, the fact is that "whether we like it or not, the species rank has a special

\footnotetext{
15 Thanks to an anonymous referee for bringing our attention to this document.

${ }^{16}$ Similarly vague turns of phrase occur elsewhere in this debate; M.R. O'Connor, for example, asks at the outset of her popular treatment of Resurrection Science: "Is a bird born of human ingenuity in the laboratory the same as a bird born of natural selection in the wild?" (2015, p. 8; our emphasis).
} 
resonance with the public and with policy-makers" (Mace 2004, p. 711). Treating species as units of conservation serves both pragmatic and political functions. When conservation measures are focused on the preservation of species, biologists must determine which species concept to employ in order to maximize their efficacy in preserving things of ecological value. Indeed, these ramifications have led conservation biologists to utilize species concepts which err on the side of species inflation, elevating groups that might otherwise count as mere populations or sub-species in order to marshall attention and resources toward their protection (Isaac, et al. 2004). The questions then arise: what are the essential features of species in their role as units of conservation, and could revived populations fulfill the pragmatic and political functions of species with respect to these interests?

In an influential discussion of the relationship between conservation and taxonomy, Mace writes:

There seems to be an emerging consensus from the species conservation-ESU [Evolutionarily Significant Unit] debate about what the units for conservation action should represent. They should be chosen to maximize the potential for evolutionary success_ and therefore to preserve adaptive diversity across the range of the taxon.... Most biologists agree that conservation must focus on preserving evolving populations in which adaptive diversity and the potential for evolutionary change is maintained. (2004, p. 714)

Interestingly, as Hey et al. argue, a species in this sense could go extinct even though living representatives of the taxon persist:

Species taxa can often be preserved in the sense of having living representatives by culturing organisms in zoos and botanical gardens; that is, by maintaining living counterparts to the taxon representatives that are kept in museums. But if species taxa are to have representatives living in nature, then they must be part of evolving populations. (2003, p. 600)

One worry is that the populations revived in typical de-extinction projects will not have the genetic diversity, independence from human involvement, or population sizes necessary for robust evolvability and therefore will not count as genuine species at all - let alone the same species as one that went extinct — in the ways that matter for conservation (Ehrenfeld 2013). However, we can imagine a de-extinction project that revives a large population and draws on significant reserves of genetic diversity, perhaps from seed banks designed for that very purpose.

A deeper worry is that if it is practically and conceptually feasible for de-extinction to bring back species in this sense, this would undermine the importance of species for conservation. Legal protections of endangered species may lose much of their justification if species can be easily resurrected any time they are allowed to go extinct; these measures would merely protect against gaps in a species (or high costs of de-extinction efforts), not the species' very existence. The proponent of 
de-extinction may reply that this is a welcome result. In the event that we can revive extinct species, the ethical and conservation value that we place on species will become and should become antiquated. We should treat them a renewable resource and not let fears of extinction interfere with other environmental or economic goals.

However, this blasé attitude toward species maintenance carries significant risks. Presently, conservation campaigns are frequently justified by their ability to prevent the extinction of species of interest, often particularly charismatic megafauna such as pandas, whales, or wolves. Even if there is nothing particularly valuable about these species in particular, the public's emotional attachment to them can be used to effectively garner public and political support for important conservation projects. Protections afforded to such "flagship" or "umbrella" species often have significant downstream effects for the preservation of important ecosystems and other threatened groups (Andelman and Fagan 2000). Plausibly, widespread acceptance of de-extinction would remove much of the impetus to marshall significant resources in defense of such flagship species and, indirectly, sacrifice the beneficial downstream consequences for ecosystems more generally.

Now, some of these risks might be mitigated. For example, conservation biologists might emphasize the importance of ecosystems as such or the harms of gaps in species persistence. Furthermore, for de-extinction projects to successfully reintroduce independent, evolvable populations, suitable habitats would still need protection, so conservationists might campaign to preserve the conditions under which polar bears could be reintroduced, rather than stressing risk of the irreversible loss of the species (Pimm 2013). Conceivably, such an approach might be more sustainable in the long term, given that the need to preserve such ecosystems would be ongoing, rather than a lost cause once charismatic species are lost (Yule 2002). Nevertheless, the worry is that easy de-extinction would promote a carelessness about species in a way that would undermine our goals of mitigating the effect that human activity has on the natural world. This is especially true when we reflect on the likely fact that even in a world where de-extinction was as easy as sequencing a genome is for us now is still not a world in which more than beloved charismatic species are returned to existence.

Such carelessness might also ignore some intrinsic value of species which cannot be restored by de-extinction. To get some sense of what this might be, consider a common rallying cry in campaigns to save endangered species: “Once they're gone, they're gone forever". Even apart from the pragmatic concerns raised above, it is doubtful that conservationists will be placated by the reasons for thinking that that's technically not true. They may admit that while species can be revived in some senses relevant to biologists, they cannot be in all of the ways that matter. Plausibly, something valuable is lost when a species goes extinct, over and above the value of each of its 
individual members. Supposing that every individual polar bear's death is a bad thing, the loss of Ursus maritimus is an additional bad thing. If this is right, what kind of value is lost when a species goes extinct, and would de-extinction projects, if successful, mitigate or nullify that loss?

Imagine a scenario in which polar bears can be brought back, but that the continued existence of the species depends on the repeated intervention of humans, such as alterations to their genome that allow them to survive in new habitats or artificial insemination of bears in captivity. One reason to think that this state of affairs would not fully restore what had been lost when polar bears originally went extinct is that perhaps some of the value of a species lies in its authenticity, where authenticity in part consists in the independent existence of a species, in a particular time and place, with a specific history (for similar proposals, see Katz 1992; Elliot 1997; Rolston 1986; 1995; see Sandler 2007 and Jebari 2016 for discussion). Sandler (2013) argues that while ethicists may disagree about the precise ground of this purported value of species, "because the ecological, intrinsic, and instrumental value of species is relational and context sensitive, deep de-extinction alone is insufficient to reestablish it" (p. 356).

By analogy, suppose that the Mona Lisa is destroyed in a fire but that we are able to reconstruct an exact, molecule-for-molecule replica of the painting. Does the Mona Lisa persist across this temporal gap? Have we still lost something valuable that has not been restored by the existence of the replica? Plausibly, the answer to the first question is "no", in part because the answer to the second question is "yes". Part of what makes the Mona Lisa valuable is its historic properties, that it was painted by actual hand of Leonardo da Vinci at a particular time and place. The replica can perhaps restore the loss of the painting's aesthetic value (as something pleasurable to look at) or can serve as the same kind for the purposes of art theorists, but it cannot restore its historical value. Therefore, relative to this kind of interest, it does not count as the same painting ${ }^{17}$.

Likewise, if part of the value of a species consists in its authenticity — in the fact that it evolved over a long period of time, accumulating spectacular adaptations to particular environmental challenges, free of human interference - then human efforts to revive the species might not restore this component of its value. This kind of loss is perhaps especially acute when the species went extinct due to human activity, such as deforestation or overfishing. We have committed a wrong, the argument goes, by destroying something that had a long, independent existence, and this is not a wrong that we can rectify by artificially creating new individuals (cf. Jebari 2016; Gyngell and Savulescu1 2016). Granted, revived "species" might have a new kind of value, just as a moon lander or any other artifact created through technological ingenuity does, but its authentic value is lost and

\footnotetext{
${ }^{17}$ Elliot (1982, p. 85) draws on a similar analogy to argue that ecological restoration projects, such as the
} reconstruction of a dune destroyed due to mining, often fail to restore the full value of what was lost. 
gone forever. On the pluralist, pragmatist account of species that we favor, the species concept that is relevant in assessing the possibility of de-extinction in a particular case will be relative to our interests. Therefore, if extinction involves the irreversible loss of an important kind of value, this will have consequences beyond just whether de-extinction is advisable but indeed for whether it is possible relative to our ethical and conservation practices.

So far, while we have seen some isolated cause for concern over the possibility of de-extinction from both metaphysical and biological perspectives, a general case against de-extinction has not emerged as a strong contender. Even if some of our goals and interests dictate the use of species concepts that legislate against gappy species in particular instances, those with pluralist leanings would presumably take this in stride. Is de-extinction possible? That depends on which species taxa you're talking about and whether gap-compatible species concepts apply to it relative to some interest or other. Since none of the various species concepts on offer conclusively precludes the possibility of de-extinction, and in many cases quite directly allow for it, we conclude that de-extinction is indeed a conceptual possibility.

\section{REFERENCES}

Andelman SJ, Fagan WF (2000). Umbrellas and Flagships: Efficient Conservation Surrogates or Expensive Mistakes? PNAS 97(11): 5954-5959

Boyd R (1999) Homeostasis, Species, and Higher Taxa. In: Wilson RA (ed) Species: New Interdisciplinary Essays. MIT Press, Cambridge,

Brogaard B (2004) Species as Individuals. Biology and Philosophy 19:223-242

Burke MB (1980) Cohabitation, Stuff and Intermittent Existence. Mind 89(355):391-405

Church G, Regis E (2012) Regenesis: How Synthetic Biology Will Reinvent Nature and Ourselves. Basic Books, New York

Crane J (2004) On the Metaphysics of Species. Philosophy of Science 71:156-173

Delord J (2007) The Nature of Extinction. Studies in the History and Philosophy of Biology and Biomedical Science 38:656-667

Delord J (2014) Can We Really Re-Create an Extinct Species by Cloning? A Metaphysical Analysis. In: Oksanen M, Siipi H (eds) The Ethics of Animal Re-Creation and Modification. Palgrave Macmillan, Houndmills,

Devitt M (2008) Resurrecting Biological Essentialism. Philosophy of Science 75(3):344-382

Donlan CJ et al. (2006) Pleistocene Rewilding: An Optimistic Agenda for Twenty-First Century Conservation. The American Naturalist 168(5):660-681

Ehrenfeld D (2013) Extinction Reversal? Don't Count On It. TEDx DeExtinction/National Geographic, Washington, D.C. http://longnow.org/revive/tedxdeextinction/

Elliot R (1982) Faking Nature. Inquiry 25(1): 81-93. Reprinted in his (1997) Faking Nature: The Ethics of Environmental Restoration. Routledge, London.

Ereshefsky M (1991) Species, Higher Taxa, and the Units of Evolution. Philosophy of Science 58:84-101 
Garvey B (2007) Philosophy of Biology. Acumen, Stocksfield

Ghiselin M (1997) Metaphysics and the Origin of Species. SUNY University Press, Albany

Gyngell C, Savulescu J (2016) Promoting Biodiversity. Philos.Technol. (DOI: 10.1007/s13347-016-0234-2)

Godfrey-Smith P (2009) Darwinian Populations and Natural Selection. Oxford University Press, Oxford

Griesemer J (1999) Materials for the Study of Evolutionary Transition. Biology and Philosophy 14(1): 127-142

Griesemer J (2000) The Units of Evolutionary Transition. Selection 1: 67-80

Griffiths PE (1999) Squaring the Circle: Natural Kinds with Historical Essences. In: Wilson RA (ed) Species: New Interdisciplinary Essays. MIT Press, Cambridge

Gunn AS (1991) The Restoration of Species and Natural Environments. Environmental Ethics 13(4):291-310

International Union for Conservation of Nature (2016) "Guiding Principles on Creating Proxies of Extinct Species for Conservation Benefit" (version 1.0); available at: https://portals.iucn.org/library/sites/library/files/documents/Rep2016-009.pdf

Hershenov DB (2003) The Metaphysical Problem of Intermittent Existence and the Possibility of Resurrection. Faith and Philosophy 20(1):24-36

Hull DL (1976) Are Species Really Individuals. Systematic Zoology 25:174-191

Hull DL (1978) A Matter of Individuality. Philosophy of Science 45:335-360

Hull DL (1981) Kitts and Kitts and Caplan on Species. Philosophy of Science 48(1):141-152

Hull DL (1983) Karl Popper and Plato's Metaphor. Reprinted in his (1989) The Metaphysics of Evolution. SUNY University Press, Albany

Isaac NJB et al. (2004) Taxonomic Inflation: Its Influence on Macroecology and Conservation. Trends in Ecology and Evolution 19(9): 464-469

Jebari K (2016) Should Extinction Be Forever? Philos. Technol. 29:211-222

Katz E (1992) The Call of the Wild. Environmental Ethics 14:265-273

Kitcher P (1984) Species. Philosophy of Science 51:308-333

Kitcher P (1989) Some Puzzles About Species. In: Ruse M (ed) What the Philosophy of Biology Is. Kluwer, Dordrecht

Kitts DB, Kitts DJ (1979) Biological Species as Natural Kinds. Philosophy of Science 46:613-622

LaPorte J (2004) Natural Kinds and Conceptual Change. Cambridge University Press, Cambridge

Lee, K (2003) Philosophy and Revolutions in Genetics: Deep Science and Deep Technology. Palgrave Macmillan, Basingstoke

Lewis D (1986) On the Plurality of Worlds. Basil Blackwell, Oxford

Lewis D (1993) Many, But Almost One. Reprinted in his Papers in Metaphysics and Epistemology. Cambridge: Cambridge University Press

Mace G (2004) The Role of Taxonomy in Species Conservation. Philosophical Transactions of the Royal Society B 359: 711-719

Mallet J (1995) A Species Definition for the Modern Synthesis. Trends in Ecology and Evolution 10(7):294-299

Martinelli L, Oksanen M, Siipi H (2014) De-extinction: a novel and remarkable case of bio-objectication. Croat Med J. 55:423-27

Mayr E (1963) Animal Species and Evolution. Harvard University Press, Cambridge 
O'Connor, M.R. (2015) Resurrection Science. St. Martin's Press, New York

O’Malley MA (2010) Ernst Mayr, the Tree of Life, and Philosophy of Biology. Biology and Philosophy 25:529-552

Okasha S (2002) Darwinian Metaphysics: Species and the Question of Essentialism. Synthese 131:191-213

Pimm S (2013) The Case Against Species Revival. National Geographic 12

Raup DM (1991) Extinction: Bad Genes or Bad Luck? W.W. Norton, New York

Reydon TAC (2003) Discussion: Species Are Individuals—Or Are They? Philosophy of Science 70:49-56

Rolston H (1986) Philosophy Gone Wild: Essays in Environmental Ethics. Prometheus, Amherst (NY)

Rolston, H (1995) Duties to Endangered Species. Encyclopedia of Environmental Biology 1:517-528

Sandler R (2013) The Ethics of Reviving Long Extinct Species. Conservation Biology 28(2):354-360

Sandler R (2007) Character and Environment: a Virtue-Oriented Approach to Environmental Ethics. Columbia University Press, New York.

Sider T (2001) Four-Dimensionalism. Oxford University Press, Oxford

Siipi H (2014) The Authenticity of Animals. The Ethics of Animal Re-Creation and Modification: Reviving, Rewilding, Restoring. Oksanen M, Siipi H (eds) Palgrave-Macmillan, Basingstoke

Siipi H, Finkleman L (2016) The Extinction and De-Extinction of Species. Philos. Technol. (DOI: 10.1007/s13347016-0244-0)

Shapiro, Beth (2015) How to Clone a Mammoth: The Science of De-Extinction. Princeton University Press, Princeton, NJ

Slater MH (2013) Are Species Real? Palgrave-Macmillan, Basingstoke

Slater MH (2015) Natural Kindness. The British Journal for the Philosophy of Science 66(2):375-411

Sokal R, Sneath P (1961) Principles of Numerical Taxonomy. Freeman, San Francisco

Turner DD (2016) De-extinction as Artificial Species Selection. Philos. Technol. (DOI: 10.1007/s13347-016-0232-4)

van Inwagen P (1978) The Possibility of Resurrection. International Journal for Philosophy of Religion 9(2):114-121

van Valen L (1976) Ecological Species, Multispecies, and Oaks. Taxon 25:233-239

Wilkerson TE (1995) Natural Kinds. Ashgate Publishing Company, Brookfield

Yashina S et al. (2012) Regeneration of Whole Fertile Plants from 30,000-year-old Fruit Tissue Buried in Siberian

Permafrost. PNAS 109(10): 4008-4013

Yule J (2002) Cloning the Extinct: Restoration as Ecological Prostheses. Common Ground 1(2): 6-9

Zimov S (2005) Pleistocene Park: Return of the Mammoth’s Ecosystem. Science 308(5723):796-798 